\title{
Removal of Phosphorus in Wastewater by Ca-Impregnated Activated Alumina
}

\author{
Seong Chul Kang, Byoung Ho Lee ${ }^{\dagger}$ \\ Department of Civil and Environmental Engineering, University of Ulsan, Ulsan 680-749, Korea
}

\begin{abstract}
Phosphorus removal during discharge of wastewater is required to achieve in a very high level because eutrophication occurs even at a very low phosphorus concentration. However, there are limitations in the traditional technologies in the removal of phosphorus at very low concentration, such as at a level lower than $0.1 \mathrm{mg} / \mathrm{L}$. Through a series of experiments, a possible technology which can remove phosphate to a very low level in the final effluent of wastewater was suggested. At first $\mathrm{Al}, \mathrm{Zn}, \mathrm{Ca}$, Fe, and Mg were exposed to phosphate solution by impregnating them on the surface of activated alumina to select the material which has the highest affinity to phosphate. Kinetic tests and isotherm tests on phosphate solution have been performed on four media, which are Ca-impregnated activated alumina, activated alumina, Ca-impregnated loess ball, and loess ball. Results showed that Ca-impregnated activated alumina has the highest capacity to adsorb phosphate in water. Scanning electron microscope image analysis showed that activated alumina has high void volume, which provides a large surface area for phosphate to be adsorbed. Through a continuous column test of the Ca-impregnated activated alumina it was discovered that about 4,000 bed volumes of wastewater with about $0.2 \mathrm{mg} / \mathrm{L}$ of phosphate can be treated down to lower than $0.14 \mathrm{mg} / \mathrm{L}$ of concentration.
\end{abstract}

Keywords: Activated alumina, Ca-impregnation, Loess, Phosphorus removal, Phosphate

\section{Introduction}

It is well known that phosphorus is an important nutrient for algal species occurring in water environments such as lakes, streams, estuaries, and even the sea [1-3]. Phosphorus discharged from a wastewater treatment plant is one of the major sources causing eutrophication in the above mentioned water environments $[1,2]$. Because phosphorus is a limiting nutrient in many cases, removal of phosphorus has been an important issue in wastewater treatments. Biological processes are normally used to reduce nitrogen and phosphorus in an advanced wastewater treatment plant. The classical methods of utilizing $\mathrm{A}_{2} \mathrm{O}$ to various modified biological processes are employed to remove the two nutrients (nitrogen and phosphorus) in domestic wastewater treatment plants [4-12]. However, phosphorus level in the effluent of wastewater treatment plant needs to be lowered further to ensure preventing eutrophication in receiving water environment. Physico-chemical processes may be applied for further removal of phosphorus in tertiary effluents. Phosphorus existing in tertiary effluent has various different types of organic and inorganic forms [13]. Particulate types of phosphorus may be flocculated by coagulants, and then removed by sedimentation [13]. Orthophosphate may also be flocculated and removed by coagulants to some extent. However, the remaining phosphate in the effluent of wastewater treatment plants is released to the environment (receiving water), so that the releasing phosphate with unsettled floc of phosphorus particles needs to be reduced further. Many studies have been performed to remove this type of low phosphorus concentration [14-20]. Park and Jung [9] used loess to remove total phosphorus in municipal wastewater, while Guo et al. [15] used iron ore to remove phosphate in dewatered liquid from sludge. Filter media have been widely used to remove phosphorus [16]. Vohla et al. [16] and Koiv et al. [17] found that material which contains high Ca content had the highest phosphorus removal capability. As a cheap material, soil may be used to remove phosphorus in the rural area of scattered villages because soil contains $\mathrm{Ca}, \mathrm{Al}$, and Fe which can combine with phosphorus [18]. Iron (Fe) is also known to be a good material to remove phosphorus in wastewater $[19,20]$. Various Ca based sorbents such as bentonite, calcium hydroxide, and Yalloun coal were used for removing phosphorus in water [21]. Naturally occurring calcium rich sepiolite was also used to remove phosphorus in water [22].

Several materials such as $\mathrm{Al}, \mathrm{Zn}, \mathrm{Ca}, \mathrm{Fe}, \mathrm{Mg}$, and loess were investigated as adsorbents for removing phosphorus in tertiary effluent in this paper. Metal cations were impregnated on the surface of activated alumina and loess ball. Out of the used materials, the best adsorbent was determined by a series of experiments. (c) This is an Open Access article distributed under the terms of the Creative Commons Attribution Non-Commercial License (http://creativecommons. org/licenses/by-nc/3.0/) which permits unrestricted non-commercial use, distribution, and reproduction in any medium, provided the original work is properly cited.
Received July 28, 2012 Accepted November 15, 2012

${ }^{\dagger}$ Corresponding Author

E-mail: bhlee@ulsan.ac.kr

Tel: +82-10-5459-0500 Fax: +82-52-259-2629 

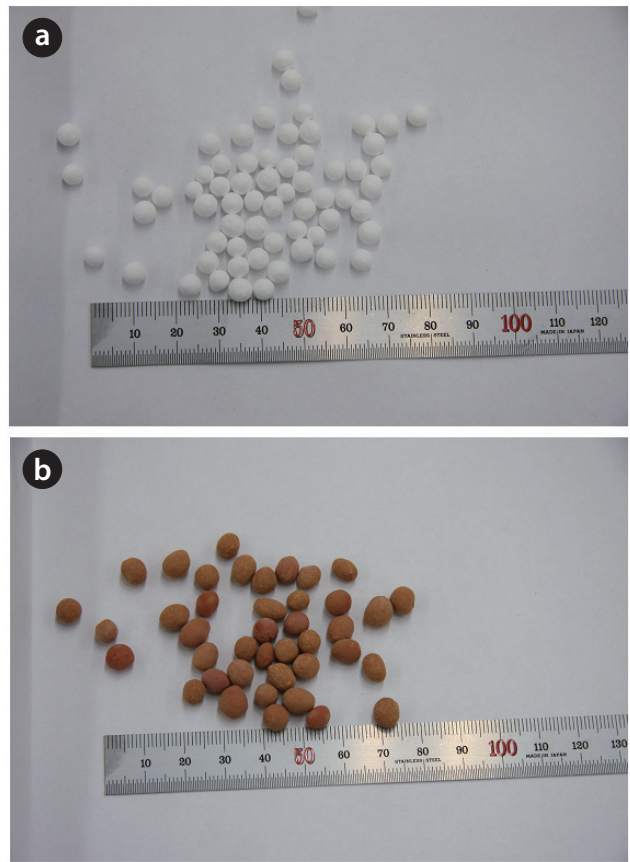

Fig. 1. Activated alumina (a), and loess ball (b) used for supporting media of impregnating metals.

\section{Material and Methods}

\subsection{Material Used in the Experiment}

Water used in synthesizing samples for isotherm tests and column tests was prepared by tap water that was distilled, and followed by passing it through an activated carbon column and ion exchange resin. The $\mathrm{pH}$ of the prepared water was 5.15.

Activated alumina and loess ball were used as a supporting media to hold the phosphate adsorbing materials (adsorbent). For phosphate adsorbing metals (adsorbents), five different impregnating chemicals were examined, i.e., $\mathrm{CaCl}_{2}$ (Yakuri Pure Chemicals, Kyoto, Japan), $\mathrm{ZnCl}_{2}$ (OCI, Seoul, Korea), $\mathrm{MgCl}_{2}$ (Junsei Chemicals, Tokyo, Japan), $\mathrm{AlCl}_{2}$ (Junsei Chemicals), and $\mathrm{FeCl}_{2}$ (Samchun Pure Chemicals, Pyeongtaek, Korea).

To determine the best media that has the highest phosphate capturing capacity, activated alumina, Ca-impregnate activated alumina, loess ball, and Ca-impregnated loess ball were tested. Activated alumina used in the experiment was made by Dryocel $848\left(\gamma-\mathrm{Al}_{2} \mathrm{O}_{3}\right.$; Porocel, Houston, TX, USA) being heated at $600^{\circ} \mathrm{C}$ for $2 \mathrm{hr}$. A loess ball of about $5 \mathrm{~mm}$ in diameter was made also by being heated at $600^{\circ} \mathrm{C}$ for $2 \mathrm{hr}$. The roasted activated alumina and loess ball were cooled in a desiccator for $24 \mathrm{hr}$. Loess used in the experiment is the material used for sedimentation to aid in water treatment plants. $\mathrm{KH}_{2} \mathrm{PO}_{4}$ (Shinyo Pure Chemicals, Osaka, Japan) was used for phosphate sample solution. Prepared activated alumina and loess ball are presented in Fig. 1. On the surface of the supporting materials as shown in Fig. 1, the above mentioned 5 adsorbents were impregnated for adsorbing phosphate in water.

\subsection{Impregnation of Adsorbing Material}

The activated alumina and loess ball were washed 3 times with deionized pure water, and they were dried in a furnace at $600^{\circ} \mathrm{C}$ for $2 \mathrm{hr}$. The dried activated alumina and loess ball were cooled in a desiccator for $24 \mathrm{hr}$. Adsorbents (metals such as $\mathrm{Al}$, $\mathrm{Zn}, \mathrm{Ca}, \mathrm{Fe}$, and $\mathrm{Mg}$ ) were impregnated on the surface of the supporting media such as the activated alumina and loess ball using a rotary vacuum evaporator (Heidolph, Schwabach, Germany) at a temperature of $80^{\circ} \mathrm{C}$, and at a pressure of $80 \mathrm{mmH}_{2} \mathrm{O}$ with $10 \mathrm{rpm}$. After impregnation, the supporting media were heated again in the furnace at $600^{\circ} \mathrm{C}$ for $2 \mathrm{hr}$ to fix the impregnated adsorbents (metals) on the surface of the supporting media of activated alumina and loess ball. The surface area and hydroxyl group of activated alumina are varied by temperature, and they were formed in the largest surface area, and in the highest density of the hydroxyl group at $300-800^{\circ} \mathrm{C}$ [23]. In this paper, supporting media (activated alumina, and loess ball) were heated at $600^{\circ} \mathrm{C}$ for shaping and impregnating adsorbents on the surface of supporting media. Impregnating metals and their concentrations are shown in Table 1.

\subsection{Experimental Methods}

\subsubsection{Phosphate adsorbing capacities of adsorbents}

Phosphate adsorbing capacities of impregnated metals (Al, $\mathrm{Zn}, \mathrm{Ca}, \mathrm{Fe}$, and $\mathrm{Mg}$ ) were measured through column test. Activated alumina of $15 \mathrm{~g}$ which were impregnated with 5 metals was filled in 5 different columns. The diameter of the column was 1.5 $\mathrm{cm}$, and the depth of the bed was $19.5 \mathrm{~cm}$. A phosphate solution $\left(\mathrm{PO}_{4}-\mathrm{P}\right), 250 \mathrm{~mL}$ of $2 \mathrm{mg} / \mathrm{L}$ was passed through the columns with $8 \mathrm{~mL} / \mathrm{min}$ of flow rate. Phosphate concentrations of effluents were measured by $0.45 \mu \mathrm{m}$ filter using an ion-chromatography (Waters, Milford, MA, USA) after they were passed through the 5 columns. The amounts of adsorbed phosphate were calculated for the five columns. The conditions of ion chromatography for phosphate analysis is presented in Table 2 .

\subsubsection{Adsorbing kinetic test}

It was revealed by the column test that $\mathrm{Ca}$ has the highest phosphate adsorbing capacity among the five metals. Because loess is known to be a good material to remove phosphorus, loess

Table 1. Metals and their concentrations used for impregnation on the surface of the two supporting media

\begin{tabular}{lcc}
\hline $\begin{array}{l}\text { Supporting } \\
\text { media }\end{array}$ & $\begin{array}{c}\text { Impregnating } \\
\text { metals }\end{array}$ & $\begin{array}{c}\text { Concentration } \\
\text { (wt. \%) }\end{array}$ \\
\hline Loess ball & $\mathrm{Ca}$ & 1.0 \\
Activated alumina & $\mathrm{Al}$ & 1.0 \\
$\left(\gamma-\mathrm{Al}_{2} \mathrm{O}_{3}\right)$ & $\mathrm{Zn}$ & 1.0 \\
& $\mathrm{Fe}$ & 1.0 \\
& $\mathrm{Mg}$ & 1.0 \\
& $\mathrm{Ca}$ & 1.0 \\
\hline
\end{tabular}

Table 2. Analysis conditions of ion-chromatography (Waters, Milford, MA, USA)

\begin{tabular}{lc}
\hline Parameter & Specification \\
\hline Column & IC-Pak Anion $\mathrm{HR}(4.6 \times 75 \mathrm{~mm})$, Waters \\
Flow rate $(\mathrm{mL} / \mathrm{min})$ & 1.0 \\
Temperature $\left({ }^{\circ} \mathrm{C}\right)$ & 35 \\
Injection volume $(\mu \mathrm{L})$ & 30 \\
Mobile phase & $1.2 \mathrm{mM} \mathrm{Na}_{2} \mathrm{CO}_{3}+1.4 \mathrm{mM} \mathrm{NaHCO}_{3}$ \\
\hline
\end{tabular}


ball was compared with activated alumina as a supporting media $[14,18]$. Phosphate adsorbing capacities of activated alumina itself, and the loess ball itself were also compared simultaneously along with those Ca impregnated ones. Amounts of phosphate adsorbed on 4 media such as Ca-impregnated activated alumina, activated alumina, Ca-impregnated loess ball, and loess ball were measured with time. Phosphate $\left(\mathrm{PO}_{4}-\mathrm{P}\right)$ solution of $5 \mathrm{mg} / \mathrm{L}$ was made with $\mathrm{KH}_{2} \mathrm{PO}_{4}$ (Shinyo pure chemicals), and was filtered by $0.45 \mu \mathrm{m}$ of $\mathrm{CF} / \mathrm{G}$ filter before being used in the experiment. Four different media of $10 \mathrm{~g}$ were allocated in $100 \mathrm{~mL}$ beaker of $5 \mathrm{mg} / \mathrm{L} \mathrm{PO}_{4}-\mathrm{P}$ solution respectively. Each beaker was mixed with $120 \mathrm{rpm}$, and samples were taken in $0.5,1,2,4,8,12,18$, and 24 $\mathrm{hr}$ at each beaker. Concentrations of phosphate in samples were measured using an ion chromatography, and removal rates with time were estimated for 4 different media.

\subsubsection{Isotherm test and scanning electron microscope investi- gation}

In order to decide the best media isotherm test has been performed for the 4 media, such as Ca-impregnated activated alumina, activated alumina, Ca-impregnated loess ball, and loess ball. The 4 media, which are Ca-impregnated activated alumina, activated alumina, and the Ca-impregnated loess ball, underwent isotherm tests to determine the best media. Each media was taken by $5 \mathrm{~g}$, and they were put in $0.1,0.5,1.0$, and $10 \mathrm{mg} / \mathrm{L}$ of $100 \mathrm{~mL}$ phosphate solutions respectively. Samples were shaken with $120 \mathrm{rpm}$ for $4 \mathrm{hr}$, and the equilibrium concentrations were measured using an ion chromatography after filtering with 0.45 $\mu \mathrm{m} C F / G$ filter. The Freundlich Model was used to estimate adsorbing capacity of the media.

Scanning electron microscope (SEM; S-2460N; Hitachi, Tokyo, Japan) was used to observe surfaces of activated alumina and the loess ball, and the Ca-impregnated activated alumina and Ca-impregnated loess ball, before and after isotherm test. Surfaces were magnified 5,000 times.

\subsubsection{Continuous column test}

After Ca-impregnated activated alumina was revealed to be the best adsorbent among 4 media by isotherm test, a continuous column test was performed. Raw water for the column test was prepared by that domestic wastewater was treated using membrane bioreactor (MBR), and the effluent of MBR system was coagulated and floated by dissolved air flotation (DAF). Effluent of the MBR-DAF system was raw water, and introduced into the column. A column, of which the effective volume was $144 \mathrm{~cm}^{3}$ with $3.5 \mathrm{~cm}$ of diameter and $15 \mathrm{~cm}$ of height, was filled with Ca-impregnated activated alumina for calculating its adsorption capacity. Solution concentration used in the column test was about $0.22 \mathrm{mg} / \mathrm{L}$ in total phosphorus (T-P), and about $0.14 \mathrm{mg} / \mathrm{L}$ in phosphate $\left(\mathrm{PO}_{4}-\mathrm{P}\right)$. Phosphorus solution was supplied until breakthrough took place in terms of T-P, and $\mathrm{PO}_{4}-\mathrm{P}$. The volume of treated water was measured by bed volumes, of which one bed volume was about $144 \mathrm{~cm}^{3}$. The schematic diagram of the column test is shown in Fig. 2.

\section{Results and Discussion}

\subsection{Decision of Impregnating Metal (Adsorbent)}

Five different metals (Al, $\mathrm{Zn}, \mathrm{Ca}, \mathrm{Fe}$, and $\mathrm{Mg}$ ) to be used for phosphate adsorption in water were impregnated on the surface

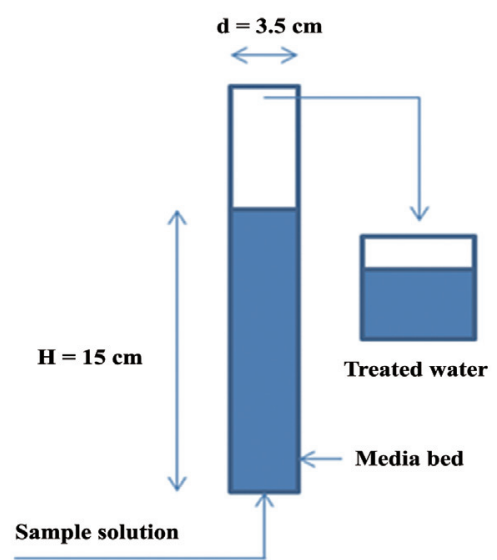

Fig. 2. Schematic diagram of the column test for Ca-impregnated activated alumina.

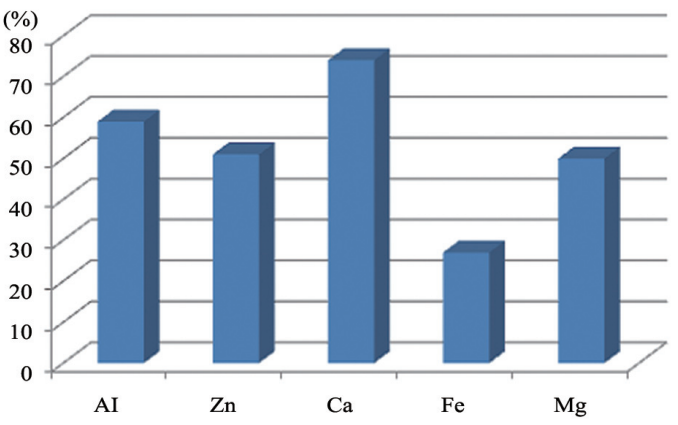

Fig. 3. Phosphate removal rates by impregnated metals on surface of activated alumina.

of activated alumina. These metals were chosen because they are known to form various complexes with phosphate [13, 14, 24]. To decide the best metal for phosphate adsorption, column tests have been performed. Synthesized phosphate solution $\left(\mathrm{PO}_{4}-\mathrm{P}\right)$, $250 \mathrm{~mL}$ of $2 \mathrm{mg} / \mathrm{L}$ was passed through the columns with $8 \mathrm{~mL} /$ min of flow rate. Each column was filled with $15 \mathrm{~g}$ of 5 specific metal-impregnated activated alumina balls as shown in Fig. 1(a). Phosphate removal rates for the 5 different columns were calculated, and compared.

Results of the column test are presented in Fig. 3. The removal rate of phosphate was highest in Ca-impregnated media as shown in Fig. 3. The order of metals with the greatest affinity to phosphate in water was $\mathrm{Ca}, \mathrm{Al}, \mathrm{Zn}, \mathrm{Mg}$, and $\mathrm{Fe}$. It was found that activated $\mathrm{Al}$ itself has high phosphate adsorbing capacity even if its affinity is lower than Ca as shown in Fig. 3. Al forms $\mathrm{AlPO}_{4}$ as a complex with phosphate, while $\mathrm{Ca}$ forms various complexes with phosphate such as $\mathrm{CaHPO}_{4}, \mathrm{Ca}\left(\mathrm{HPO}_{4}\right)_{2}$, and $\mathrm{Ca}_{5}\left(\mathrm{PO}_{4}\right)_{3} \mathrm{OH}$, etc. [13, 21, 22]. Thus Ca was selected as an impregnating metal on the surface of the supporting media.

\subsection{Kinetics of Phosphate Adsorption}

Adsorbing velocity is important to decide the size of the reacting column. If adsorbing velocity is slow, the size of the reacting column should be larger. Kinetics of phosphate adsorption were 


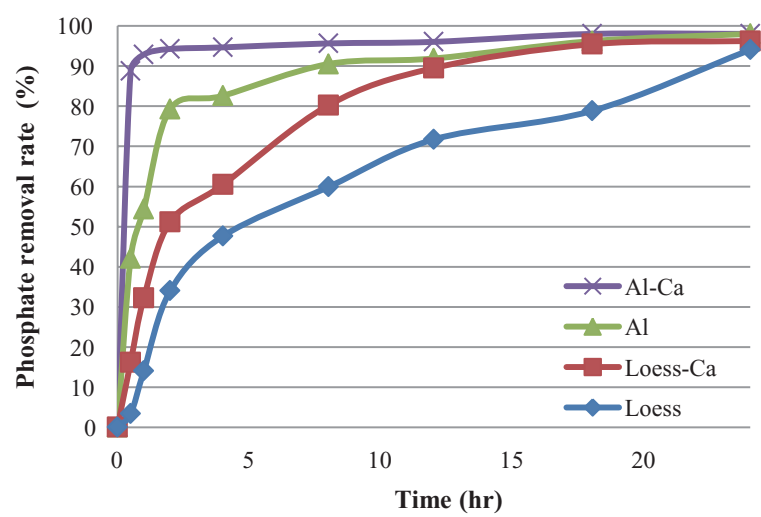

Fig. 4. Phosphate removal rate variations with time by 4 media (Caimpregnated activated alumina, activated alumina, Ca-impregnated loess ball, and loess ball).

tested for 4 different media such as Ca-impregnated activated alumina $\left(\mathrm{Al}_{2} \mathrm{O}_{3}+\mathrm{Ca}\right), \mathrm{Al}_{2} \mathrm{O}_{3}$, Ca-impregnated loess ball (loess $+\mathrm{Ca}$ ), and loess ball. As shown in Fig. $4, \mathrm{Al}_{2} \mathrm{O}_{3}+\mathrm{Ca}$ has the highest velocity for adsorption of phosphate in a sample water. About $93 \%$ of $\mathrm{PO}_{4}-\mathrm{P}$ was removed in an hour by Ca-impregnated alumina, while $54 \%$ was removed by activated alumina and $32 \%$ removed by the Ca-impregnated loess ball and only $14 \%$ removed by loess ball. There was about a 39\% difference in removal rate with and without Ca-impregnation on the surface of activated alumina. About $95 \%$ of phosphate was adsorbed within $2 \mathrm{hr}$ by $\mathrm{Al}_{2} \mathrm{O}_{3}+\mathrm{Ca}$, while less than $80 \%$ of phosphate was adsorbed by activated alumina. The order of adsorbing velocity from the highest was $\mathrm{Al}_{2} \mathrm{O}_{3}+\mathrm{Ca}$, activated alumina, loess $+\mathrm{Ca}$, and loess. This adsorbing velocity order was formed due to their order of affinity to phosphate in water [13]. Adsorbing reaction may take place in 3 different stages as follows: the first stage occurs in $1 \mathrm{hr}$ which is a rapid reaction, the second stage from one hour to about $12 \mathrm{hr}$, which is a time limiting reaction, and the third stage occurs after $12 \mathrm{hr}$, which is a retarded reaction $[13,25]$. This different time delaying reaction may take place by constituents on the surface of adsorbing media. Ionic bonds take place in several seconds, so that impregnated $\mathrm{Ca}^{2+}$ on the surface of media reacts readily with $\mathrm{HPO}_{4}{ }^{2-}[13,21,22]$. The precipitation reaction of $\mathrm{AlPO}_{4}$ may need a longer period of time than an ionic bond reaction. And other complex reactions such as heterogeneous complexation and/or replacement reaction may take place very slowly [11, 21, 22]. And new sites may be generated continuously as the adsorbing reaction proceeds $[24,25]$.

\subsection{Isotherm Tests for 4 Media}

An isotherm test was performed for 4 media, which are Caimpregnated activated alumina, activated alumina, Ca-impregnated loess ball, and loess ball to estimate adsorption capacities. Phosphorus adsorption may be influenced by $\mathrm{pH}$ of the water, so that $\mathrm{pHs}$ of samples were measured along with equilibrium phosphorus concentrations. Fig. 5 shows $\mathrm{pH}$ change and amount of adsorbed phosphorus in isotherm tests. $\mathrm{pH}$ tends to be increased with increasing introduced media. It is analyzed that $\mathrm{OH}^{-}$was released from the introduced media such as Ca-impregnated activated alumina, activated alumina, Caimpregnated loess ball, and loess ball, which raised pHs of the samples during the experiments like Fig. 5(a). More adsorbents
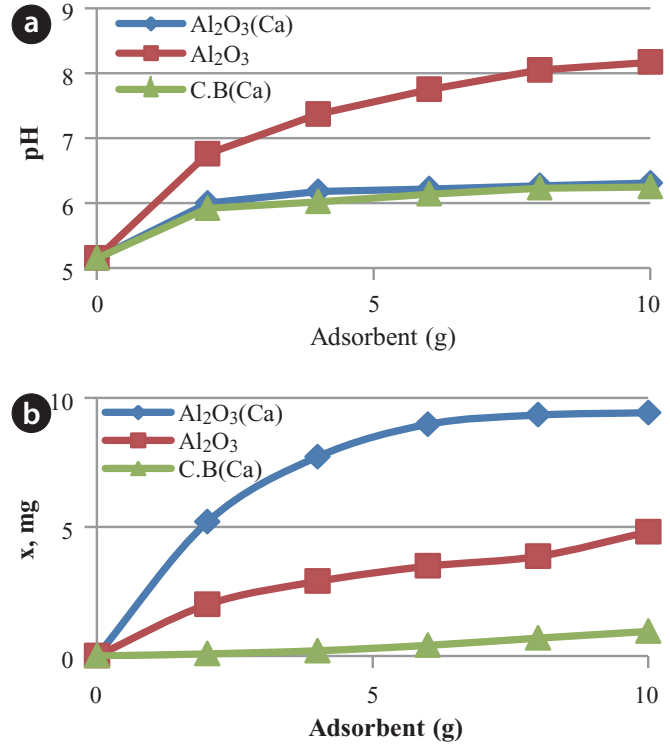

Fig. 5 . pH changes (a) and adsorbed phosphorus amounts (b) with introduced adsorbents.

introduced resulted in higher pH of the samples. Even though the adsorbed amount of phosphorus tended to increase with $\mathrm{pH}$, they were not directly proportional to each other. Even if the $\mathrm{pH}$ of the activated alumina sample was raised to the highest with introduced weight of media like Fig. 5(a), the adsorbed amount of phosphorus was not the highest as shown in Fig 5(b).

Ca-impregnated activated alumina turned out to have the highest capacity in phosphate adsorption as it can be seen in Fig. 5. Activated alumina also showed high phosphate adsorption capacity even though its capacity was lower than that of Ca-impregnated activated alumina. Even though Ca was impregnated on the surface of loess as the same way with that of activated alumina, the phosphate adsorption capacity of the Ca-impregnated loess ball was much lower than that of the Ca-impregnated activated alumina. Loess ball had the lowest phosphate adsorption capacity among the 4 media. Even though loess is known to be a good phosphate adsorbent $[14,17,18]$, its capacity was much lower than activated alumina. The reason why activated alumina has a higher phosphate adsorption capacity seems to be because activated alumina has a larger surface area than loess. Also, electrical attraction of activated alumina against phosphate may be stronger than that of loess. Results of the isotherm test are presented in Fig. 6 . The adsorbed amount of phosphate per unit weight (g) has increased consistently in Ca-impregnated activated alumina with the increased phosphate concentration as shown in Fig. 6. Adsorbed amount of phosphate $(\mathrm{x} / \mathrm{m})$ was much less in the loess ball with the increase of phosphate concentration as can be seen in Fig. 6. Activated alumina was a better media than loess in the adsorption of phosphate, and Ca-impregnated media was a better adsorbent than that without Ca-impregnation. The order of descending phosphate adsorption capacity starting with the greatest was Ca-impregnated activated alumina, activated alumina, Ca-impregnated loess, and loess ball, respectively.

It was analyzed that activated alumina has a higher affinity to phosphate (stronger electrical attraction), and larger surface area than that of loess. Results show that Ca has a higher affinity 
to phosphate than $\mathrm{Al}$ as in Fig. 6. Consequently, Ca-impregnated activated alumina should be the best adsorbent among the four tested media.

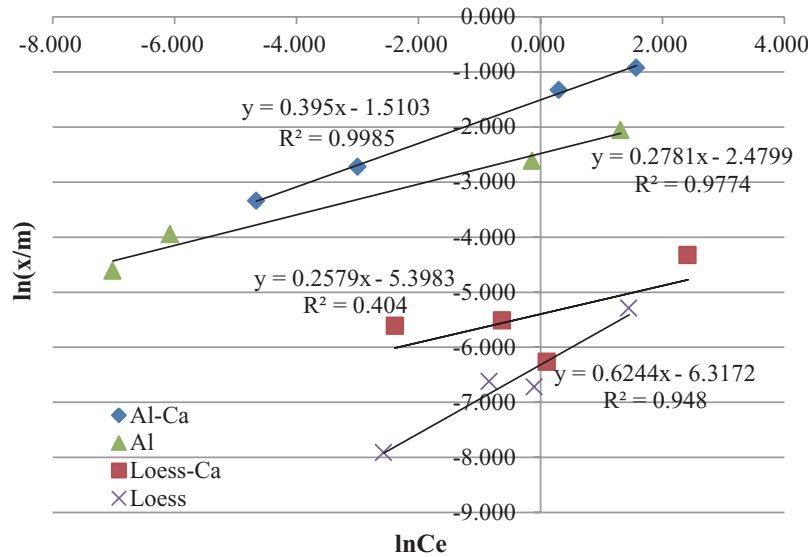

Fig. 6. Results of isotherm for 4 media (Ca-impregnated activated alumina, activated alumina, Ca-impregnated loess ball, and loess ball).

\subsection{SEM Image Analysis}

Surface SEM images of two media, activated alumina and loess ball were taken as shown in Fig. 7. Image in Fig. 7(a) represents the surface of activated alumina, and Fig. 7(b) shows loess ball before Ca-impregnation. Both images were magnified 5,000 times. The surface of activated alumina looks very rough, and has enormous voids like Fig. 7(a), while that of loess ball looks smooth, and does not show much voids on the surface like Fig. 7(b). It may be assumed that activated alumina, which has a larger surface area, provides a larger area for Ca to be impregnated on the surfaces compared to the loess ball.

Ca was impregnated on the surfaces of activated alumina and loess ball at the same conditions using a rotary vacuum evaporator (Heidolph) at $80^{\circ} \mathrm{C}$, and at a pressure of $80 \mathrm{mmH}_{2} \mathrm{O}$ with $10 \mathrm{rpm}$. Impregnated amounts of Ca were $1 \%$ in weight basis for both activated alumina and loess ball, so that the amounts of impregnated Ca were the same. Impregnated surfaces of activated alumina and loess ball are shown in Fig. 8. Ca seemed to be accumulated more on the surface of the loess ball in Fig. 8(b) than on that of activated alumina in Fig. 8(a). However, analysis revealed that Ca was precipitated on the surface of the loess ball with several layers, while precipitated Ca on the surface of activated alumina was penetrated into the void of activated alumina in-
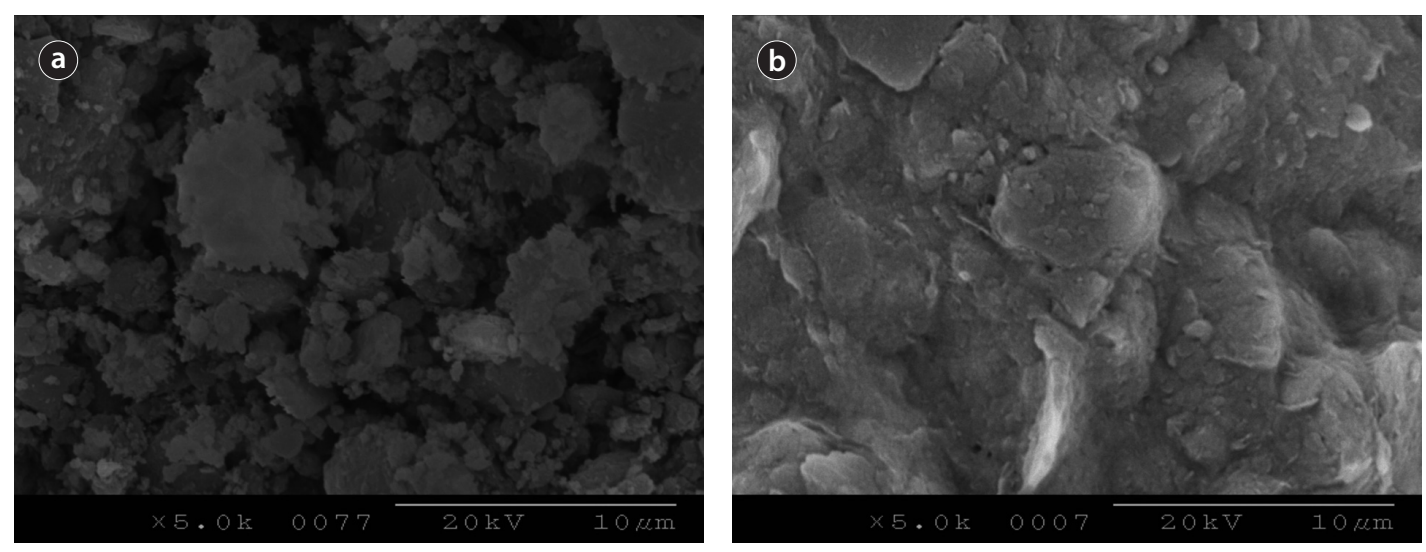

Fig. 7. Surface scanning electron microscope images of activated alumina (a), and loess ball (b) (5,000 times magnification).
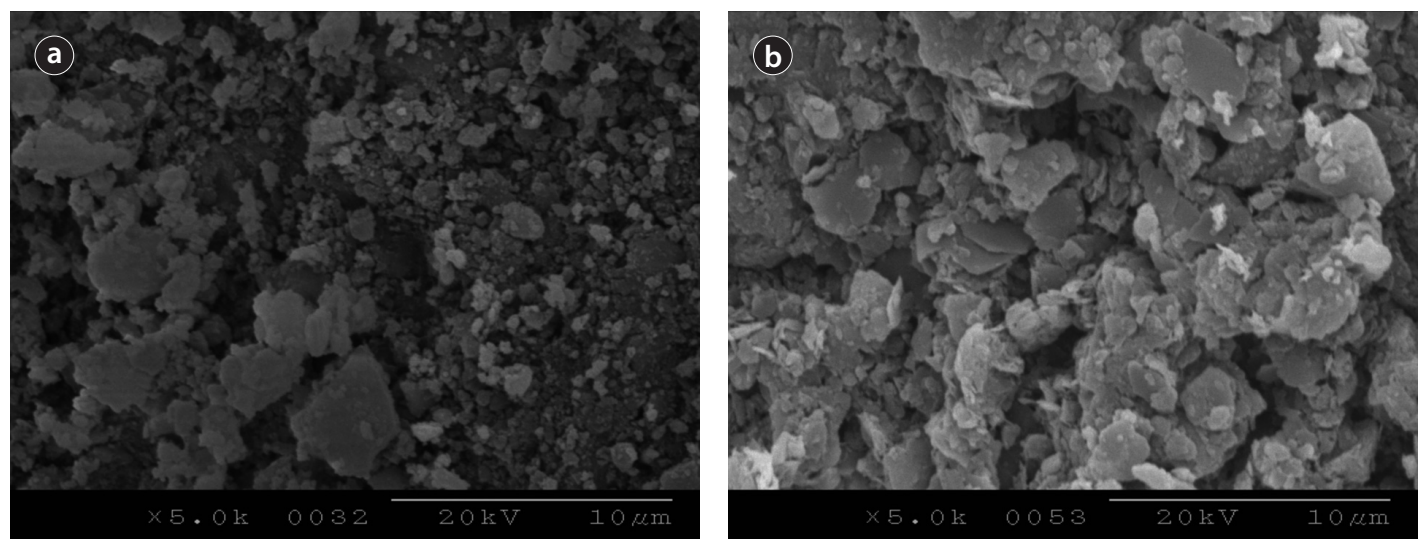

Fig. 8. Scanning electron microscope images of Ca-impregnated activated alumina (a) and loess ball (b) before isotherm adsorption test for phosphate solution (5,000 times magnification). 

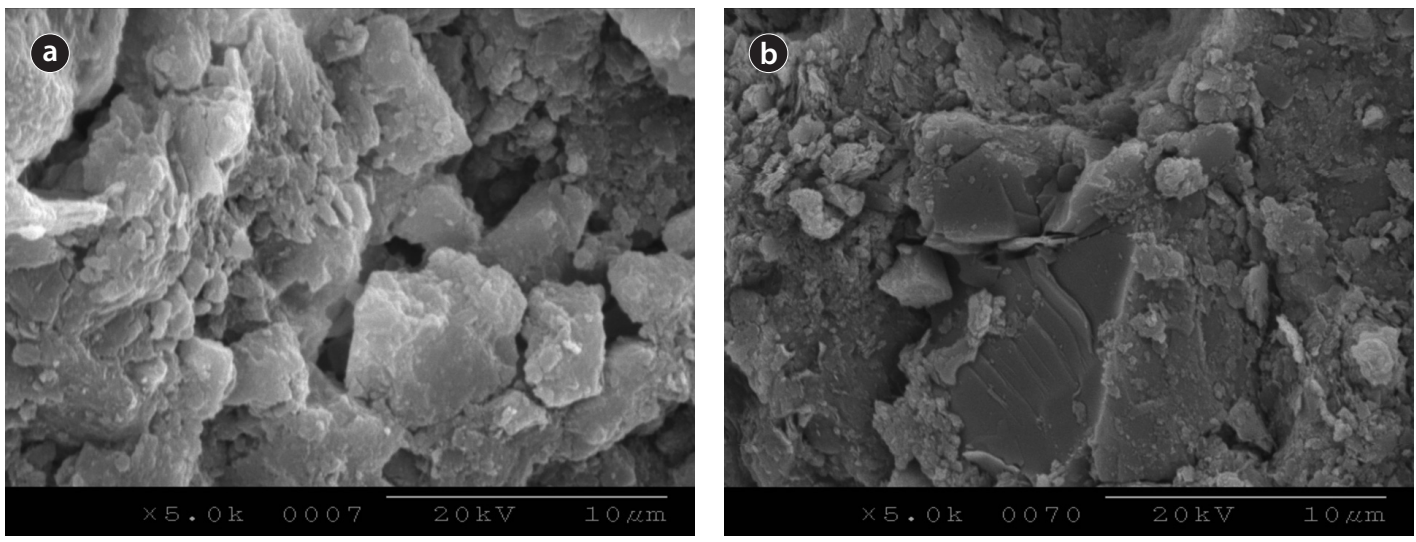

Fig. 9. Surface scanning electron microscope images of phosphate precipitated activated alumina (a) and loess ball (b) after isotherm adsorption test for phosphate solution (5,000 times magnification).

side, as in Fig. 8. Phosphate was supposed to be adsorbed on the Ca-impregnated surfaces of the two media. The Ca-impregnated activated alumina and Ca-impregnated loess ball were exposed to phosphate solutions as Fig. 8 for isotherm adsorption tests.

Phosphate precipitated surfaces of activated alumina and loess ball are shown in Fig. 9. Heavily precipitated phosphate with several layers can be seen on the surface of activated alumina in Fig. 9(a). The phosphate precipitated surface of activated alumina looks much more rough than that of the loess ball, and much more phosphate seems to have been precipitated. The phosphate precipitated surface in Fig. 9(b) looks smoother and the precipitated phosphate looks lighter than that of activated alumina like Fig. 9(a). The SEM image analyses are similar to those of isotherm tests. The precipitated amount of phosphate per unit weight of activated alumina was larger than that of the loess ball in the isotherm test. Even if the amount of impregnated $\mathrm{Ca}$ is the same as in the weight basis, the surface area of the activated alumina is larger than that of the loess ball, and the electrical attraction of activated alumina may be greater than that of the loess ball. These two factors resulted in a higher adsorption rate of phosphate in activated alumina than in the loess ball as visualized in SEM image analysis.

\subsection{Continuous Column Test}

A continuous column test had been performed with Caimpregnated activated alumina which turned out to be the best adsorbents on phosphate among the various options. Raw water was prepared using domestic wastewater from a nearby wastewater treatment plant to simulate the actual field system. Solution concentration (raw water) used in the column test was about $0.22 \mathrm{mg} / \mathrm{L}$ in $\mathrm{T}-\mathrm{P}$, and about $0.14 \mathrm{mg} / \mathrm{L}$ in phosphate $\left(\mathrm{PO}_{4}^{-}\right.$ $\mathrm{P})$. A phosphorus solution was supplied until breakthrough took place in terms of T-P, and $\mathrm{PO}_{4}-\mathrm{P}$. The volume of treated water was measured by bed volumes, of which one bed volume was about $144 \mathrm{~cm}^{3}$. The result of the column test is presented in Fig. 10. Breakthrough of T-P took place when the phosphate reached breakthrough as can be seen in Fig. 10, which means that adsorbed phosphorus was phosphate $\left(\mathrm{PO}_{4}{ }^{2-}\right)$ in the solution, and the Ca-impregnated surface of activated alumina reacted only with phosphate. It was proven that the surface of the activated alumina was well activated to adsorb phosphate.

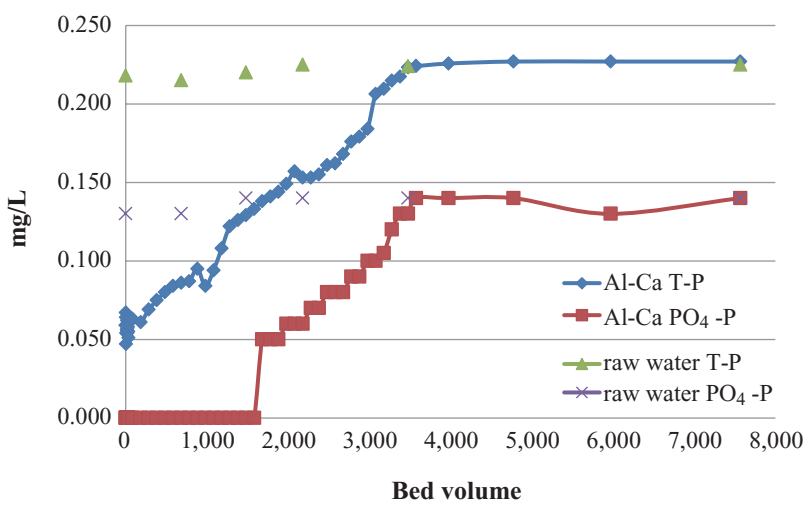

Fig. 10. Breakthrough curves of total phosphorus (T-P) and phosphate $\left(\mathrm{PO}_{4}{ }^{2-}\right)$ for Ca-impregnated activated alumina.

Ca-impregnated activated alumina may be used till 4,000 bed volumes with solution used in the investigation takes place at breakthrough. The solution concentration used in the investigation was decided by the fact that secondary effluent concentration after chemical precipitation is around $0.2 \mathrm{mg} / \mathrm{L}$. Organic phosphorus and particulate phosphorus contained in floc may be retained by membrane filtration. However, the remaining phosphate may not be removed very well. Such ionic phosphorus can be removed by adsorption using appropriate media like Ca-impregnated activated alumina used in the investigation. In such a way, particulate phosphorus and ionic phosphorus may be removed down to extremely low concentrations in the final discharge of wastewater.

\section{Conclusions}

The remaining phosphorus in discharging wastewater needs to be removed to prevent eutrophication in receiving water. Because eutrophication may occur even in very low phosphorus concentrations, the remaining phosphorus in discharging the effluent of wastewater is required to be removed down to a very low concentration. Ca-impregnated activated alumina is used to remove phosphate in very low concentrations. 
$\mathrm{Ca}, \mathrm{Al}, \mathrm{Zn}, \mathrm{Mg}$, and Fe were tested for possible option to adsorb phosphate in water. Out of these 5 metals Ca turned out to be the best adsorbent to adsorb phosphate in water. Ca was impregnated on the surfaces of activated alumina and loess ball for the purpose of selecting the appropriate supporting media, and they were compared in their performances. By kinetic tests on Ca-impregnated activated alumina, activated alumina, Caimpregnated loess ball, and loess ball, it was found that the order of greatest affinity to phosphate in water was Ca-impregnated activated alumina, activated alumina, Ca-impregnated loess ball, and loess ball. Isotherm adsorption tests showed phosphate adsorption capacities of the above 4 media have the same order as affinities to phosphate in water in the case of a kinetic test. Ca-impregnated activated alumina has the highest capacity to adsorb phosphate in water. The reason that Ca-impregnated activated alumina has the highest capacity was visualized by SEM image analysis. Along with a higher affinity to phosphate, activated alumina has high a volume of voids, which provides a large surface area for phosphate to be precipitated than loess ball does. Ca-impregnated activated alumina may be used till 4,000 bed volumes with phosphate solution of $0.2 \mathrm{mg} / \mathrm{L}$ used in the investigation takes place at breakthrough.

Finally, it was discovered that the effluent of wastewater with very low phosphorus concentration can be achieved using Caimpregnated activated alumina adsorption along with other filtration processes.

Further investigations should be performed to incorporate economic aspects because the investigation has been performed only on a lab scale.

\section{References}

1. Bonsdorff E, Blomqvist EM, Mattila J, Norkko A. Coastal eutrophication: causes, consequences and perspectives in the Archipelago areas of the northern Baltic Sea. Estuar. Coast. Shelf Sci. 1997;44:63-72.

2. Ferreira JG, Andersen JH, Borja A, et al. Overview of eutrophication indicators to assess environmental status within the European Marine Strategy Framework Directive. Estuar. Coast. Shelf Sci. 2011;93:117-131.

3. Smith VH. Using primary productivity as an index of coastal eutrophication: the units of measurement matter. J. Plankton Res. 2007;29:1-6.

4. Fan J, Tao T, Zhang J, You G. I. Performance evaluation of a modified anaerobic/anoxic/oxic $\left(\mathrm{A}^{2} / \mathrm{O}\right)$ process treating low strength wastewater. Desalination 2009;249:822-827.

5. Zeng W, Li L, Yang YY, Wang XD, Peng YZ. Denitrifying phosphorus removal and impact of nitrite accumulation on phosphorus removal in a continuous anaerobic-anoxic-aerobic (A2O) process treating domestic wastewater. Enzyme Microb. Technol. 2011;48:134-142.

6. Kim D, Kim KY, Ryu HD, Min KK, Lee SI. Long term operation of pilot-scale biological nutrient removal process in treating municipal wastewater. Bioresour. Technol. 2009;100:31803184.

7. Zhang Z, Li H, Zhu J, Weiping L, Xin X. Improvement strategy on enhanced biological phosphorus removal for municipal wastewater treatment plants: full-scale operating parameters, sludge activities, and microbial features. Bioresour. Technol. 2011;102:4646-4653.

8. Zeng W, Yang Y, Li L, Wang X, Peng Y. Effect of nitrite from ni- tritation on biological phosphorus removal in a sequencing batch reactor treating domestic wastewater. Bioresour. Technol. 2011;102:6657-6664.

9. Monclus H, Sipma J, Ferrero G, Rodriguez-Roda I, Comas J. Biological nutrient removal in an MBR treating municipal wastewater with special focus on biological phosphorus removal. Bioresour. Technol. 2010;101:3984-3991.

10. Guo CH, Stabnikov V, Ivanov V. The removal of nitrogen and phosphorus from reject water of municipal wastewater treatment plant using ferric and nitrate bioreductions. Bioresour. Technol. 2010;101:3992-3999.

11. Yang S, Yang F, Fu Z, Wang T, Lei R. Simultaneous nitrogen and phosphorus removal by a novel sequencing batch moving bed membrane bioreactor for wastewater treatment. $J$. Hazard. Mater. 2010;175:551-557.

12. Harvey S, Dixon M. Biological hydrogen production: simultaneous saccharification and fermentation with nitrogen and phosphorus removal from wastewater effluent. Int. J. Hydrogen. Energy 2010;35:9611-9617.

13. Snoeyink VL, Jenkins D. Water chemistry. New York: Wiley; 1980.

14. Park JH, Jung DI. Removal of total phosphorus (TP) from municipal wastewater using loess. Desalination 2011;269:104110.

15. Guo C, Stabnikov V, Kuang S, Ivanov V. The removal of phosphate from wastewater using anoxic reduction of iron ore in the rotating reactor. Biochem. Eng. J. 2009;46:223-226.

16. Vohla C, Koiv M, Bavor HJ, Chazarenc F, Mander U. Filter materials for phosphorus removal from wastewater in treatment wetlands: a review. Ecol. Eng. 2011;37:70-89.

17. Koiv M, Liira M, Mander U, Motlep R, Vohla C, Kirsimae K. Phosphorus removal using Ca-rich hydrated oil shale ash as filter material: the effect of different phosphorus loadings and wastewater compositions. Water Res. 2010;44:5232-5239.

18. Liang H, Liu J, Wei Y, Guo X. Evaluation of phosphorus removal from wastewater by soils in rural areas in China. J. Environ. Sci. (China) 2010;22:15-22.

19. Ruihua L, Lin Z, Tao T, Bo L. Phosphorus removal performance of acid mine drainage from wastewater. J. Hazard. Mater. 2011;190:669-676.

20. Dobbie KE, Heal KV, Aumonier J, Smith KA, Johnston A, Younger PL. Evaluation of iron ochre from mine drainage treatment for removal of phosphorus from wastewater. Chemosphere 2009;75:795-800.

21. Khadhraoui M, Watanabe T, Kuroda M. The effect of the physical structure of a porous Ca-based sorbent on its phosphorus removal capacity. Water Res. 2002;36:3711-3718.

22. Yin H, Yun Y, Zhang Y, Fan C. Phosphate removal from wastewaters by a naturally occurring, calcium-rich sepiolite. $J$. Hazard. Mater. 2011;198:362-369.

23. Kawasaki N, Ogata F, Takahashi K, Kabayama M, Kakehi K, Tanada S. Relationship between anion adsorption and physicochemical properties of aluminum oxide. J. Health Sci. 2008;54:324-329.

24. Yamada H, Kayama M, Saito K, Hara M. A fundamental research on phosphate removal by using slag. Water Res. 1986;20:547-557.

25. Hameed BH, Mahmoud DK, Ahmad AL. Sorption of basic dye from aqueous solution by pomelo (Citrus grandis) peel in a batch system. Colloids Surf. A Physicochem. Eng. Asp. 2008;316:78-84. 